\title{
VISIBILIDADE DO RISCO PSIQUICO EM CRIANÇAS NA ATENÇÃo PRIMÁRIA
}

\author{
Visibility of psychic risk in children in Primary Care
}

\author{
Isabel Cristina Soder ${ }^{1}$, Inês Terezinha Pastório² ${ }^{2}$ Giseli Cipriano Rodacoski ${ }^{3}$ \\ 1. Psicóloga pela UFPR. Especialista em Educação Especial pela UNIOESTE - campus Marechal Cândido \\ Rondon e em Psicanálise Clínica pela PUCPR- campus Toledo. https://orcid.org/0000-0001-5229-5881 \\ 2. Assistente Social pela UNIOESTE. Pesquisadora do Grupo de Estudo e Pesquisa em Políticas Ambientais \\ e Sustentabilidade (GEPPAS) e do Grupo Interdisciplinar e Interinstitucional de Pesquisa e Extensão em \\ Desenvolvimento Sustentável (UNIOESTE). Mestre e Doutoranda em Desenvolvimento Rural Sustentável \\ (PPGDRS), pela UNIOESTE, Campus de Marechal Cândido Rondon. https://orcid.org/0000-0002-4449- \\ 2591 \\ 3 Psicóloga, Mestre em Educação, Doutora em Biotecnologia - linha de pesquisa: Ensino na Saúde. \\ Professora na Escola de Saúde Pública do Paraná. Curitiba-PR. ORCID: https://orcid.org/0000-0003- \\ 4837-9331
}

CONTATO: Isabel Cristina Soder | Avenida Maripá, 6999/7001 | Toledo | PR | (45) 33791449 | isabelsoder@hotmail.com

COMO CITAR Soder IC, Pastório IT, Rodacoski GC. Visibilidade do risco psíquico em crianças na atenção primária. R. Saúde Públ. 2019 Jul.;2(Suppl 2): 47-52

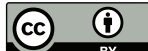

COPYRIGHT Esta obra é disponibilizada nos termos da Licença Creative Commons - 4. 0

Internacional. É permitida a reprodução parcial ou total desta obra, desde que citada a fonte.

RESUMO A fim de sensibilizar e esclarecer possíveis sinais de sofrimento psíquico em bebês, ou algum tipo de risco à saúde mental, com vistas a uma estimulação a tempo, o presente Projeto Aplicativo tem como objetivo realizar um acompanhamento permanente de uma Unidade de Atenção Primária de Saúde (UAPS) de um território. A metodologia utilizada para elaboração foi pesquisa bibliográfica e de dados acerca da realidade do município e suas necessidades. Para a execução do projeto, a metodologia escolhida foi ações de matriciamento, através dos itens/sinais que estão contemplados nos Indicadores Clínicos de Risco para o Desenvolvimento Infantil (IRDI). Como resultado é esperada a conscientização dos profissionais da atenção primária acerca da necessidade de acompanhamento da saúde mental dos bebês e suas famílias, como também ações que possam envolver a Rede de Atenção Psicossocial (RAPS), para uma estimulação a tempo neste aspecto. 
PALAVRAS-CHAVE: Criança. Saúde Mental. Continuidade de Assistência ao Paciente. Desenvolvimento Infantil.

ABSTRACT In order to sensitize and clarify possible signs of mental suffering in infants, or any type of risk to mental health, aiming at timely stimulation, the present Application Project aims to carry out permanent monitoring of a Primary Health Care Unit of a territory. The methodology used for elaboration was bibliographical and data research about the reality of the municipality and its needs. For the project implementation, the chosen methodology was matriciation actions, through the items/signs that are contemplated in the Clinical Indicators of Risk (IRDI) for Child Development. Regarding the results, these cannot be presented because it is a pilot project to be developed; however, it is expected that the primary care professionals become aware of the need to monitor the mental health of the babies and their families, as well as actions that may involve the Psychosocial Care Network (RAPS) for timely stimulation in this regard.

KEYWORDS: Child. Mental Health. Continuity of Patient Care. Child Development.

\section{INTRODUÇÃO}

$\mathbf{0}$

documento aqui apresentado versa sobre um Projeto Aplicativo, desenvolvido e apresentado ao Programa de PósGraduação da Escola de Saúde Pública do Paraná - Curso de Especialização em Saúde Mental na Atenção Primária à Saúde.

A intervenção a tempo é necessária assim que observados os primeiros sinais indicando que a inserção na cultura não está ocorrendo, havendo comportamentos no bebê que rejeitam de alguma forma o afeto e os vínculos com as figuras próximas.

Acreditamos que, conforme alguns estudos, algumas intervenções em relação às figuras de afeto e no ambiente relacional possam auxiliar na diminuição do sofrimento psíquico do bebê em início de construção.
Diante deste pressuposto, foi pesquisado sobre os indicadores possíveis e encontrado o IRDI, que aparentou maior consonância aos aspectos acreditados do desenvolvimento do psiquismo humano. Além disso, o mesmo encontra-se em consonância com novas leis que protegem o desenvolvimento integral das crianças.

Diante deste desafio, e com as políticas públicas de saúde, educação e assistência social, a criança, como sujeito de direitos, tem papel principal sendo prioridade absoluta para atendimento, necessitando que os serviços se articulem para garantir o cumprimento do Estatuto da Criança e do Adolescente. Para isso, observamos com maior carinho o trabalho das Unidades Primárias de Saúde, com projetos como o da Mãe Paranaense que prevê visitas ao 
recém-nascido e acompanhamento durante os primeiros anos de vida em relação a sua saúde integral.

Torna-se importante esta aproximação da atenção primária com o campo da saúde mental, ampliando a rede de atendimento e acompanhamento nos processos de cuidado, fazendo jus a Política de Saúde Pública.

Os CAPS, que são componentes estratégicos da saúde mental pública, têm dentre suas atribuições realizar o apoio matricial. Neste sentido o presente projeto faz parte da política de desinstitucionalização psiquiátrica e ao mesmo tempo uma questão de acesso integral à saúde, em seu próprio território, comunidade, voltandose a prevenção de transtornos e/ou agravos de quadros de transtorno mental também ao público infantil no quesito prevenção.

Assim como ações de prevenção e reinserção, a articulação com os territórios acaba se tornando um campo de atuação importante, tanto no descobrimento precoce e assim evitando agravos, quanto também ao seu encaminhamento e orientações.

Sendo criado com os objetivos acima expostos.Embora haja certa resistência de alguns estudiosos quanto ao uso indiscriminado de protocolos onde constam os sinais de risco (IRDI), ou outros, optamos por valorizar a relevância do conhecimento que este pode contribuir com os profissionais de saúde quanto às intervenções em tempo, e até mesmo justificando a criação de serviços especializados e a elaboração do Projeto Terapêutico Singular (PTS), ou plano de cuidados em saúde mental, envolvendo não somente instituições especializadas, como toda a rede da comunidade (RAPS).

Neste sentido, ampliando a observação dos bebês para além dos itens previstos na Rede Mãe Paranaense, longe de rotular ou culpabilizar as mães, podem ser estabelecidos contatos saudáveis e acolhimento da rede quanto à maternagem.

Levando em conta a abordagem teórica escolhida para este trabalho, a criança está num processo de construção de sua subjetividade, e a intervenção a tempo (até 4 anos) pode ser feita mais facilmente, pelo fato da dificuldade em seu desenvolvimento ser possivel de passar por recursos de criação ou restauração de condições favoráveis para a saúde mental da criança. Além disso, a abordagem neuropsicológica fala da plasticidade cerebral maior nesta época da vida

Mesmo sendo preconizado no Estatuto da Criança e Adolescente (ECA) que o IRDI, ou outro protocolo de identificação precoce, seja utilizado nas consultas pediátricas, a noção de desenvolvimento e construção do aparelho psíquico e a intervenção a tempo beneficiam todos os envolvidos com a saúde mental e RAPS.

O Projeto de Aplicação aqui proposto como uma ação integrada entre os serviços se tornará uma ferramenta essencial, tanto para o melhor desenvolvimento infantil, quanto para a prevenção de agravos, e cumprimento das metas da política pública do município.

Segundo Lancetti², o matriciamento acontece com parcerias entre equipes de saúde mental ou de Núcleo de Apoio à Saúde da Família (NASF) e a Estratégia da Saúde da Família (ESF) ou Atenção Primária à Saúde (APS), sendo o usuário responsabilidade destas equipes, parceria que necessita ser construída.

\section{METODOLOGIA}

A metodologia de um projeto abrange tanto teorias como um conjunto de técnicas para torná-la realidade. São inseparáveis, articulam a realidade com hipóteses e conteúdos. No 
que se refere às técnicas, estas devem ser um "instrumental claro, coerente, elaborado, capaz de encaminhar os impasses teóricos para o desafio da prática"³.

A metodologia escolhida para a realização do presente projeto foi primeiramente a pesquisa bibliográfica, com a finalidade de obter informações sobre o tema. Para a execução do projeto elegeu-se o denominado apoio matricial, por ser uma das atividades do Centro de Atenção Psicossocial (CAPS), e contemplar conhecimentos específicos de uma especialidade para profissionais de outras áreas, com a finalidade de acolhimento integral das demandas em saúde das crianças.

Melo ${ }^{4}$, em seu material sobre apoio matricial na Atenção Primária, lembra que quem matricia também é matriciado. Este trabalho implica em produzir arranjos que articulam todas as tecnologias pedagógicas e clínico-assistenciais e situações concretas, com vistas a ampliar a capacidade de cuidado de uma equipe de ESF ou APS. 0 mesmo autor, cita Merhy ${ }^{5.4}$, que fala que nesta ação a tecnologia a ser utilizada é a classificada como leve, pois não depende de aparelhagem e sim do campo relacional, momentos de acolhimento, de produção de vínculo e responsabilização, ocorrendo apenas durante o matriciamento propriamente dito. Implica em abertura e organização poderem coexistir, impedindo o enrijecimento e ao mesmo tempo dar matéria para as ações.

Durante a reunião de matriciamento será realizada a explanação dos 31 itens que compõem o protocolo IRDI aos Agentes Comunitários de Saúde (ACS) e equipe da APS/ESF interessada, ocorrendo a explicação dos itens e sobre o desenvolvimento da criança de até 18 meses.

Será exposto também que o protocolo em si só será aplicado em casos justificados pelas relações observáveis entre mãe e bebê e a presença de sinais. De preferência acompanhadas pela Rede Mãe Paranaense, ou por solicitações.

No que se refere aos recursos humanos, físicos, serão necessários profissionais de saúde com conhecimentos sobre o desenvolvimento psíquico infantil da própria Secretaria de Saúde Profissionais da UAPS e/ou ESF e Usuários da Rede Mãe Paranaense. Quanto aos físicos, será necessário um local para que as etapas sejam realizadas, e que preferencialmente elas possam ser na UBS ou em sala da Escola de Administração Pública, oportunizado em horário ou turno de trabalho dos profissionais. Os recursos financeiros serão pequenos, pois será utilizada estrutura própria da UAPS ou outra estrutura pública e materiais já disponíveis como: Multimídia (do próprio local ou CAPS) com acesso à internet autorizado pelo setor de informática da Prefeitura de Toledo, documentários, folhas sulfite para anotações gerais (cerca de 10 por participante), canetas, fotocópia de material produzido anteriormente para dar suporte para as discussões.

\section{RESULTADOS}

Este trabalho não tem fins quantitativos, nem de diagnóstico, objetivando a conscientização de um olhar diferenciado aos aspectos contemplados no IRDI.

Percebe-se que a utilização de métodos clínicos isolados sem levar em conta o todo, no sentido da integralidade da pessoa em sua comunidade, família e escola, não alcançam os objetivos em questões que se tornam cruciais para o desenvolvimento das potencialidades das crianças em risco de/ou em sofrimento psíquico.

No documento sobre o Fórum Nacional de 
Saúde Mental Infantojuvenil é recomendada a articulação entre os setores de saúde e educação, para ações no que diz respeito à educação inclusiva, respeitando a política de inclusão do MEC, que orienta sistemas de ensino inclusivos para todos os alunos com transtornos mentais e outros tipos de deficiências.

No que tange à Saúde mental e à atenção primária, o documento ressalta a importância de os CAPS se articularem à rede do PSF e da atenção primária e ambulatorial, de modo a cumprir os princípios e as diretrizes da política de saúde mental do território. Através do matriciamento, nas unidades básicas de saúde, pode ser promovido o fluxo dos usuários na rede de serviços e a comunicação entre profissionais da saúde nos encaminhamentos ${ }^{5}$.

Desta maneira, este Projeto de Aplicação cumpre os objetivos da Reforma Psiquiátrica, do Estatuto da Criança e do Adolescente, assim como nas políticas públicas, justificando-se assim a sua implantação.

Além disso, o projeto se justifica devido à importância em haver identificação e intervenção precoce nos casos de sinais de risco psíquico observáveis já nos primeiros 18 meses de vida da criança. Aumentando os conhecimentos dos profissionais de saúde a este respeito, a probabilidade de diminuição de preconceitos e intervenção a tempo para diminuição de agravos é significativa.

\section{DISCUSSÃO}

O projeto mostra-se viável por sua importância ao desenvolvimento integral infantil, pelo fato de existirem usuários que se beneficiarão e componentes das equipes interessados em saúde mental, além de o projeto ser de baixo custo para o Município, pois serão convidados profissionais da rede para o desenvolvimento e abordagem dos temas e conteúdos propostos, havendo uma significativa melhora na qualidade do atendimento e redução de danos.

A grande demanda de trabalho dos profissionais é uma variável impeditiva para a execução do projeto, e realizá-lo fora do horário deste muitas vezes desmotiva o profissional, inviabilizando o propósito a que se destina.

Ao final da execução deste projeto, os profissionais poderão sentir a importância de olharem as demandas em saúde mental também na UB, e sentirem-se capacitados em poder observar sinais de risco psíquico em crianças acompanhadas, modos de acolhimento e sobre dar informações sobre a intervenção a tempo e encaminhamentos se necessários. Durante os encontros de matriciamento será possível identificar e mapear possíveis casos que necessitem de intervenção em saúde mental.

Acompanhando o desenvolvimento de tarefas ao longo de um determinado tempo, formulando hipóteses sobre o observado e através da análise dos indicadores será possível obter informações sobre os resultados.

Através do levantamento de dados do número de casos encaminhados para avaliação de especialistas no início do processo e os detectados após as explicações sobre os indicadores pode-se inferir a eficácia do processo.

O Estatuto da Criança e do Adolescente prevê todos os aspectos para o desenvolvimento pleno das crianças e adolescentes, prevendo remoção de obstáculos a ele sempre que necessário.

O Ministério da Saúde aponta a atenção 
primária como um conjunto de ações de saúde que abrangem a promoção e a proteção da saúde, prevenção de agravos, diagnósticos, tratamento, reabilitação e manutenção da saúde. Sendo a saúde mental um aspecto transversal e intersetorial, é necessário que seja feito o trabalho em rede de todos os dispositivos que existirem nas diversas áreas municipais. Este pode ser propiciado através do matriciamento que é uma das atribuições dos CAPS.

Assim como ações de prevenção e reinserção, a articulação com os territórios acaba se tornando um campo de atuação importante, tanto no descobrimento precoce e assim evitando agravos, quanto também ao seu encaminhamento e orientações.

Mostra-se um projeto viável para transformação e melhora da realidade existente, sendo de grande importância a saúde mental dos cidadãos do município.

\section{CONCLUSÃO}

A perspectiva de saúde integral da criança torna-se condição primeira para compreender a importância da intervenção a tempo, na busca da prevenção ou diminuição de agravos.

Com este intuito, somente com um acompanhamento da criança com intervalos breves nos primeiros meses de vida, observando os primeiros sinais de que algo não vai bem, no que se refere às primeiras relações afetivas, seria possivel intervir de forma positiva.

Com o processo da desinstitucionalização psiquiátrica, a figura do cidadão torna-se central diante da comunidade, família e os serviços que o cercam. Gerando a constituição de uma rede de cuidados pautados no respeito à individualidade e direito ao tratamento pelo setor público.
Assim, considera-se este trabalho como sendo de grande importância, pois prevê o acolhimento do indivíduo em formação e os diversos braços que o cercam, sendo capaz de gerar mudanças nestes segmentos para, então, olhar com singularidade para este ou estes que sofrem com a dificuldade em se constituir integralmente como sujeito ativo em sua própria história e na capacidade em estabelecer e manter laços sociais.

\section{REFERÊNCIAS}

1. Kupfer MCM et al. (2009). Valor preditivo de indicadores clínicos de risco para o desenvolvimento infantil: um estudo a partir da teoria psicanalítica. Latin American Journal of Fundamental Psychopathology Online, 6(1), 48-68. [ Links ]

2. Lancetti A. Curso de Aperfeiçoamento em Saúde Mental. Mod. 3 - O Projeto Terapêutico Singular e o Trabalho de Matriciamento. ED. UNA - SUS/UNIFESP, 2015.

3. Minayo MCS, Deslandes SF, Gomes R. PESQUISA SOCIAL: Teorias, métodos e criatividade. 30ª Ed. Petrópolis, RJ: Vozes, 2011.

4. Melo EA, org. Trabalho em equipe na perspectiva da organização e pactuação inicial do trabalho. In Melo, EA, org. Caderno do Curso de Apoio Matricial na Atenção Básica com Ênfase nos NASF: Aperfeiçoamento. $2^{a}$ Ed. Rio de Janeiro-RJ: EAD/ENSP/FIOCRUZ, 2016.

5. Ministério da Saúde (BR). Secretaria de atenção à saúde. Departamento de Atenção Especializada e Temática. Fórum Nacional de Saúde Mental Infantojuvenil: Recomendações de 2005 a 2012. Brasilia -DF 2014. 